\title{
Penerapan Quick Response (QR) Code Berbasis Web Di Puskesmas Payung Sekaki Pekanbaru
}

\author{
Ken Rio Agizki', Regiolina Hayami²*, Harun Mukhtar ${ }^{3}$ \\ ${ }^{123}$ Fakultas Ilmu Komputer,Universitas Muhammadiyah Riau \\ email :kenrioagizki@gmail.com¹, regiolinahayami@umri.ac.id², harunmukhtar@umri.ac.id ${ }^{3}$
}

\begin{abstract}
Puskesmas staffing data certainly cannot be separated from data that can change at any time. Changes to the data must be stored properly. At Puskesmas Payung Sekaki the attendance system is still using paper as an employee attendance data file, so that frequent loss of data and double data on absenteeism makes mistakes for the staffing of Puskesmas Payung Sekaki. Supporting Puskesmas staff every day must go to the Puskesmas to attend attendance when they come and go home, so that fraud arises in making attendance by making attendance care.Attendance system using the QR Code, can easily search data and minimize fraud in attendance care, because the QR Code must scan. The QR Code scanning results will be saved in the database. The QR Code is made with the Puskesmas Employee Identification Number. The results obtained from the Implementation of the Quick Response $(Q R)$ Code for the attendance of Puskesmas are able to facilitate employees in making attendance and the head of administration to get information on the attendance of Puskesmas Payung Sekaki employees.
\end{abstract}

Keywords : QR Code, Attendance, Puskesmas, Payung Sekaki

\begin{abstract}
Abstrak
Data kepegawaian puskesmas pastinya tidak lepas dari data-data yang dapat berubah sewaktuwaktu. Perubahan data tersebut harus tersimpan dengan baik. Pada Puskesmas Payung Sekaki sistem absensi yang dilakukan masih menggunakan kertas sebagai arsip data absensi pegawai, sehingga sering terjadinya kehilangan data dan d ata ganda pada absensi yang menjadikan kekeliruan bagi bagian kepegawaian Puskesmas Payung Sekaki. Pegawai Puskesmas Pembantu setiap hari harus ke Puskesmas untuk melakukan absensi pada saat datang dan pulang, sehingga timbul kecurangan dalam melakukan absensi dengan melakukan penitipan absensi. Sistem absensi menggunakan QR Code ini, dapat dengan mudah melakukan pencarian data dan meminimalisir terjadinya kecurangan dalam penitipan absensi, karena QR Code harus melakukan scanning. Hasil scanning QR Code akan tersimpan di database. QR Code tersebut dibuat dengan Nomor Induk Pegawai Puskesmas. Hasil yang didapat dari Penerapan Quick Response (QR) Code untuk absensi Puskesmas adalah dapat mempermudah pegawai dalam melakukan absensi dan kepala tata usaha untuk mendapatkan informasi kehadiran pegawai Puskesmas Payung Sekaki.
\end{abstract}

Kata Kunci : QR Code, Absensi, Puskesmas, Payung Sekaki.

\section{Pendahuluan}

Menurut Kamus Besar Bahasa Indonesia (KBBI), Aplikasi adalah penerapan dari rancang sistem untuk mengolah data yang menggunakan aturan atau ketentuan bahasa pemrograman tertentu. Aplikasi merupakan suatu perkembangan teknologi untuk mendukung operasi dan manajemen. Salah satu perkembangan teknologi yaitu dengan menggunakan $Q R$ Code. Menurut [1] Quick Response Code atau yang biasa disebut dengan $Q R$ Code merupakan sebuah barcode dua dimensi yang diperkenalkan oleh Perusahaan Jepang Denso Wave pada tahun 1994. Pada dasarnya bahwa $Q R$ Code dikembangkan sebagai suatu kode yang memungkinkan isinya untuk dapat diterjemahkan dengan kecepatan tinggi. Menurut David (2003), Keunggulan dari $Q R$ Code adalah mampu menyimpan informasi secara horizontal dan vertikal.

Dalam data kepegawaian Puskesmas pastinya tidak lepas dari data-data yang dapat berubah sewaktu-waktu. Perubahan data 
tersebut harus tersimpan dengan baik. Dalam pengelolaan data kebanyakan dari pihak Puskesmas dan Dinas Kesehatan seperti data cuti pegawai, data absensi, data pegawai mutasi serta data tugas untuk pegawai masih menggunakan sistem pemrosesan manual, sehingga kemungkinan untuk kehilangan data sangat besar. Pemanfaatan sistem informasi bagi pihak Puskesmas, akan membantu Puskesmas dalam menjaga kualitas informasi yang membantu dalam proses administrasi pengelolaan data- data tersebut. Dalam hal ini data tersebut akan bermanfaat dan memudahkan bagi Puskesmas untuk mengelola data dengan baik, dan memudahkan bagian kepegawaian dalam mengelola data pegawai yang masih menggunakan sistem yang manual.

Pada Puskesmas Payung Sekaki sistem absensi yang dilakukan masih menggunakan kertas sebagai arsip data absensi pegawai, sehingga sering terjadinya kehilangan data dan data ganda pada absensi yang menjadikan kekeliruan bagi bagian kepegawaian Puskesmas Payung Sekaki. Di Puskesmas Payung Sekaki terdapat satu cabang Puskesmas, yang disebut Puskesmas Pembantu. Pegawai Puskesmas Pembantu setiap hari harus ke Puskesmas pusat untuk melakukan absensi pada saat datang dan pulang. Maka dari itu dibuatlah sistem absensi sebagai media bagi bagian kepegawaian dan pegawai Puskesmas Payung Sekaki untuk mendapatkan data absensi dan memudahkan pegawai Puskesmas Pembantu untuk melakukan absensi. Tujuan adanya sistem ini untuk memudahkan pegawai Puskesmas Pembantu melakukan absensi dan memudahkan bagian kepegawaian untuk mendapatkan dan mencari data absensi para pegawai.

Kedepannya dengan adanya sistem absensi di Puskesmas Payung Sekaki ini diharapkan dapat memudahkan untuk mendapatkan data dan melakukan pencarian data absensi. Sistem yang baru ini juga mudah diakses kapan dan dimana saja, dengan menggunakan smartphone android dan $Q R$ Code yang menjadi media untuk melakukan absensi, dapat terhubung ke sistem yang akan dibuat, dan secara otomatis akan menjadi arsip absensi untuk bagian kepegawaian. QR Code memiliki kelebihan tingkat kerapatan tinggi, kapasitas informasi yang dapat di masukan besar dan informasi yang di tanamkan terdiri dari URL, SMS, alamat email, huruf jepang, dsb. Sistem ini juga dapat menjadi sebuah inovasi dalam melakukan absensi yang menjadi media absensi dan penyimpanan data absensi bagi Puskesmas Payung Sekaki.

\section{Metodologi Penelitian}

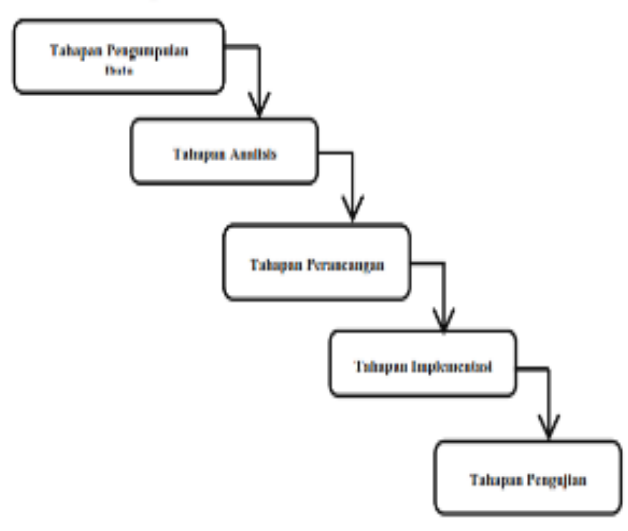

Gambar 1. Tahapan Metode Waterfall Menurut Sommerville (2003)

Menurut [2] Model waterfall adalah model klasik yang bersifat sistematis, berurutan dalam membangun software. Nama model ini sebenarnya adalah "Linear Sequential Model". Model ini sering disebut juga dengan "classic life cycle" atau metode waterfall. Model ini termasuk ke dalam model generik pada rekayasa perangkat lunak dan pertama kali diperkenalkan oleh Winston Royce sekitar tahun 1970 sehingga sering dianggap kuno, tetapi merupakan model yang paling banyak dipakai dalam Software Engineering (SE). Model ini melakukan pendekatan secara sistematis dan berurutan. Disebut dengan waterfall karena tahap demi tahap yang dilalui harus menunggu selesainya tahap sebelumnya dan berjalan berurutan.

\subsection{Tahapan Pengumpulan Data}

Adapun teknik pengumpulan data yang digunakan adalah:

1. Wawancara

Peneliti melakukan tanya jawab dengan mengajukan pertanyaanpertanyaan kepada pemilik secara lisan mengenai bagaimana proses perancangan sistem informasi pada 
Puskesmas Payung Sekaki Pekanbaru, yang berhubungan dengan penyusunan dan pelaksanaan penelitian.

2. Studi Pustaka

Peneliti melakukan pencarian dan pengumpulan data dengan cara membaca buku, pembelajaran dari berbagai macam literature dan dokumen yang menunjang kegiatan penelitian ini berkaitan dengan sistem informasi.

\subsection{Tahapan Analisa Sistem}

Pada Puskesmas Payung Sekaki sistem absensi yang dilakukan masih menggunakan kertas sebagai arsip data absensi pegawai, sehingga sering terjadinya kehilangan data dan data ganda pada absensi yang menjadikan kekeliruan bagi bagian kepegawaian Puskesmas Payung Sekaki. Maka dari itu dibuatlah sistem absensi sebagai media bagi bagian kepegawaian dan pegawai Puskesmas Payung Sekaki untuk mendapatkan data absensi dan memudahkan pegawai Puskesmas Pembantu untuk melakukan absensi. Aplikasi yang baru ini dapat digunakan di smartphone android dan QR Code yang menjadi media untuk melakukan absensi, dapat terhubung ke sistem yang akan dibuat, dan secara otomatis akan menjadi arsip absensi untuk bagian kepegawaian.

\subsection{Tahapan Perancangan Sistem}

Pada tahapan perancangan aplikasi ini menggunakan Unified Modeling Language (UML) sebagai alat bantu. UML yang digunakan dalam melakukan perancangan ini adalah Aliran Sistem Informasi (ASI), Konteks Diagram, Data Flow Diagram (DFD). Pada Aliran Sistem Informasi (ASI) ini akan dijelaskan bagaimana alur aplikasi yang dibuat. Konteks Diagram ini menjelaskan gambaran umum tentang aplikasi. Data Flow Diagram (DFD) ini akan dijelaskan apa saja yang dapat dilakukan oleh user dan apa saja yang terdapat dalam aplikasi ini

\begin{tabular}{|c|c|}
\hline Pegawai & Kepala Tata Usaha \\
\hline
\end{tabular}

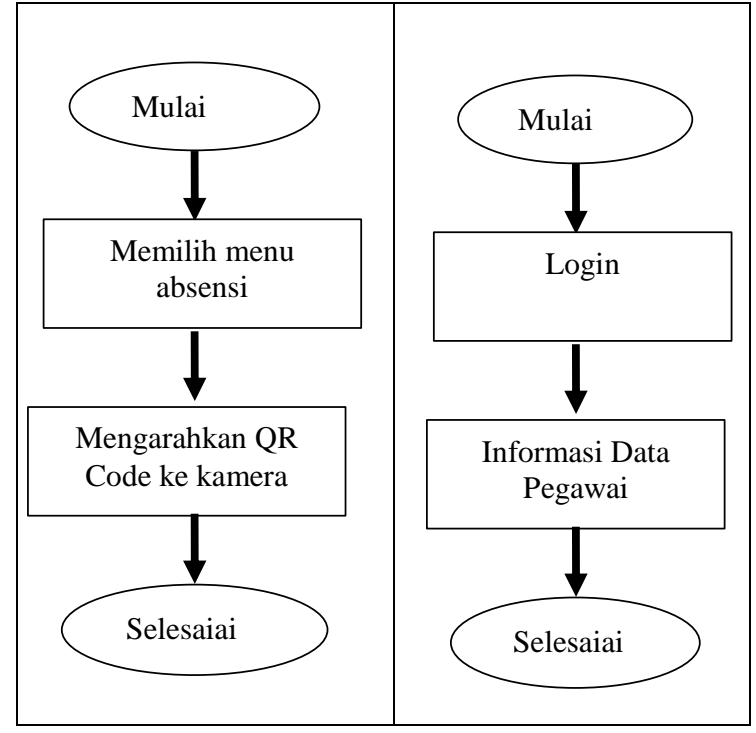

Gambar 2. Gambaran Umum Sistem

\subsection{Tahapan Pembuatan Sistem}

Tahapan ini adalah pemecahan masalah yang telah dirancang kedalam bahasa pemrograman dengan membuat source code aplikasi yang akan dibangun dalam hal ini menggunakan PHP, XAMPP, dan App Creator. PHP digunakan untuk pembuatan kode program dalam aplikasi ini, XAMPP digunakan sebagai penampil halaman aplikasi yang telah dibuat serta tempat penyimpanan database dan App Creator digunakan sebagai pembuatan website menjadi aplikasi di smartphone.

\subsection{Tahapan Pengujian Sistem}

Pada tahapan ini aplikasi di uji sebagai aplikasi yang lengkap untuk menjamin bahwa persyaratan aplikasi telah terpenuhi. Pengujian yang dilakukan terhadap aplikasi yaitu pengujian dengan metode black-box.

\section{Hasil dan Pembahasan}

Perancangan sistem bertujuan untuk memberikan gambaran sistem yang dibuat. Perancangan disini terdiri dari perancangan database, pembuatan sistem, implementasi sistem dan pengujian sistem.

\subsection{Perancangan Database}

Menurut [3] menjelaskan bahwa "Database diartikan sebuah koleksi atau kumpulan data yang saling berhubungan (relation), disusun menurut aturan tertentu secara logis, sehingga menghasilkan informasi".

Untuk menggambarkan simpanan data yang ada di dalam sistem, maka dibuat suatu database dengan nama absensi, yang 
mempunyai rancangan tabel yang berisi fieldfield, tipe data dan lebar yang terdapat dalam sistem. Adapun tabel-tabel yang digunakan yaitu, tabel admin, tabel pegawai dan tabel absensi.

\subsection{Pembuatan Sistem}

Pembuatan sistem dilakukan dengan menggunakan Sublime Text dan XAMPP dengan bahasa pemrograman PHP Murni. Menurut [4] Sublime Text adalah aplikasi editor untuk kode dan teks yang dapat berjalan diberbagai platform operating sistem dengan menggunakan teknologi Phyton API. Terciptanya aplikasi ini terinspirasi dari aplikasi Vim, Aplikasi ini sangatlah fleksibel dan powerfull. Menurut [5] dalam bukunya yang berjudul Pemrograman Web Dengan PHP, menyebutkan bahwa : "XAMPP ( $\mathrm{X}$ (windows/linux) Apache MySQL PHP dan Perl) merupakan paket server web PHP dan database MySQL yang paling popular dikalangan pengembang web dengan menggunakan PHP dan MySQL sebagai databasenya. Menurut [6] PHP native merupakan pemrograman web perpaduan bahasa pemrograman yang didasari dengan bahasa pemrograman PHP yang mana bisa disisipi oleh text Javascript, CSS, Bootstrap dan lain-lain. Native sendiri artinya asli, yakni pemrograman PHP yang murni disusun dan di coding/dibangun oleh para programmer sendiri tanpa ada istilah tambahan buat settingan/konfigurasi lainnya. Berikut ini adalah penjelasan tentang pembuatan sistem:

1. Hal pertama yang dilakukan untuk pembuatan sistem adalah pembuatan halaman utama dengan menggunakan file login.php, yaitu sebagai halaman utama yang akan tampil saat menjalankan sistem.

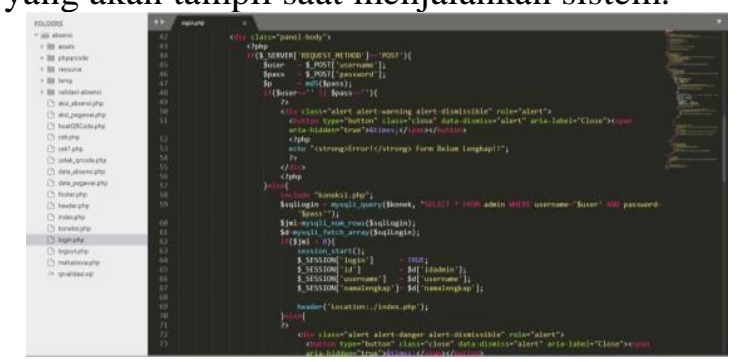

Gambar 3. Pembuatan Halaman Utama Sistem

Setelah pembuatan halaman utama, maka dilakukan pembuatan halaman-halaman berikutnya, seperti pembuatan halaman beranda, halaman data pegawai, halaman data absensi dan halaman tambah absensi. Berikut ini adalah gambar dari source code halaman beranda, halaman data pegawai, halaman data absensi dan halaman tambah absensi.

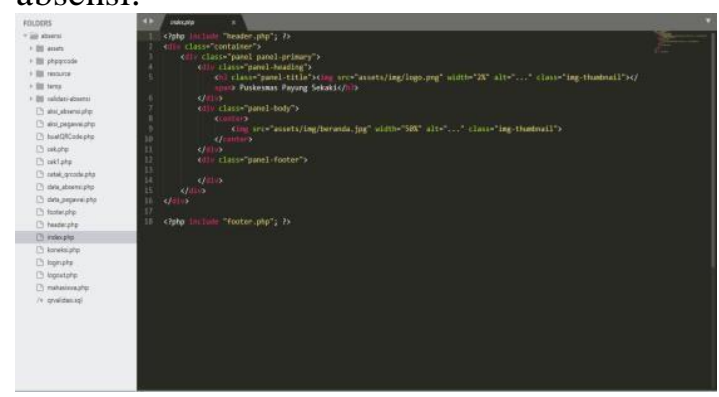

Gambar 4. Pembuatan Halaman Beranda Sistem

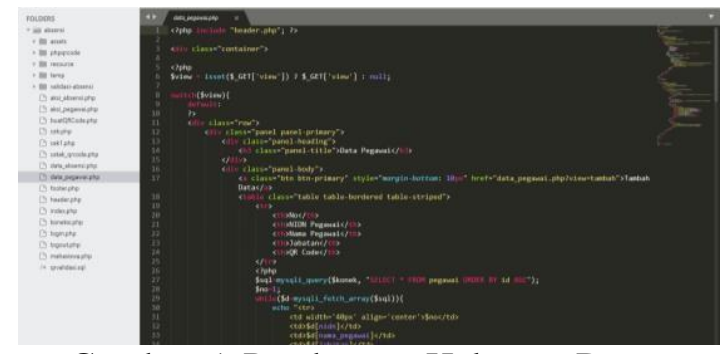

Gambar 5. Pembuatan Halaman Data

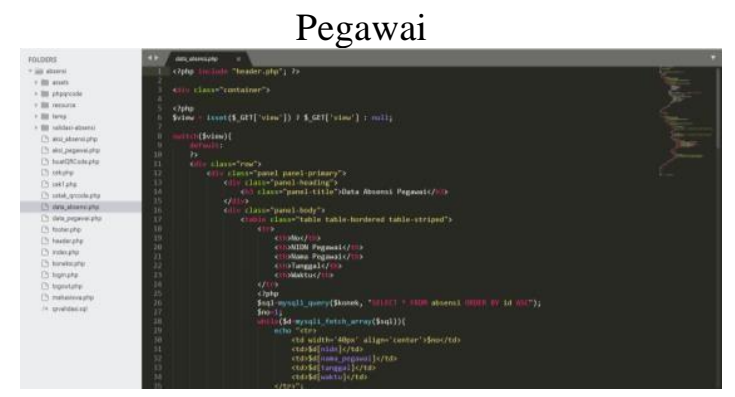

Gambar 6. Pembuatan Halaman Data Absensi

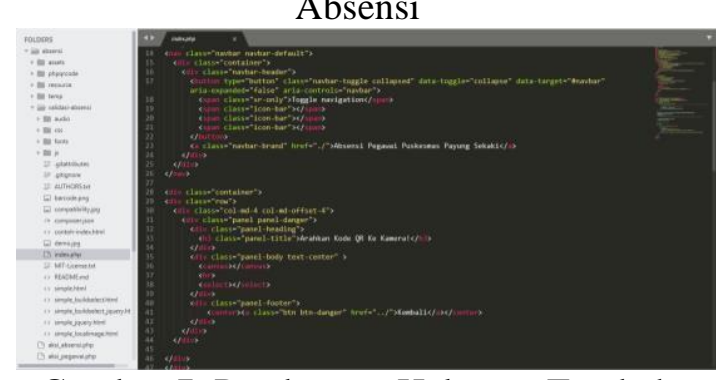

Gambar 7. Pembuatan Halaman Tambah Absensi

2. Setelah seluruh halaman sistem dibuat, yang harus dilakukan adalah menghubungkan database dengan sistem agar data yang tersimpan di dalam database tampil di sistem. Untuk menghubungkannya dilakukan pembuatan file koneksi.php. Berikut ini adalah gambar dari file koneksi.php. 


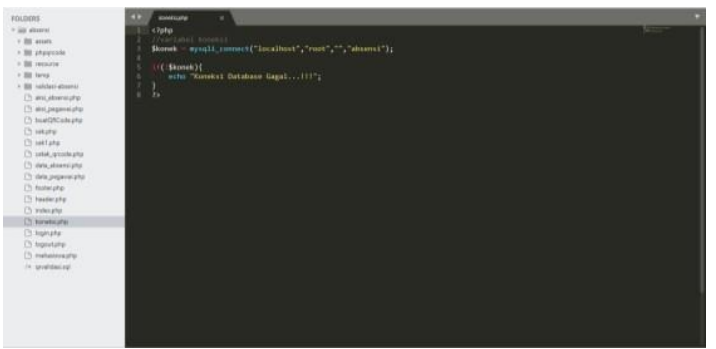

Gambar 8. Menghubungkan Database dan Sistem

3. Setelah database dan sistem terhubung dilakukan pembuatan file buatqrcode.php untuk pembuatan QR Code masing-masing pegawai. Berikut adalah gambar dari buatqrcode.php.

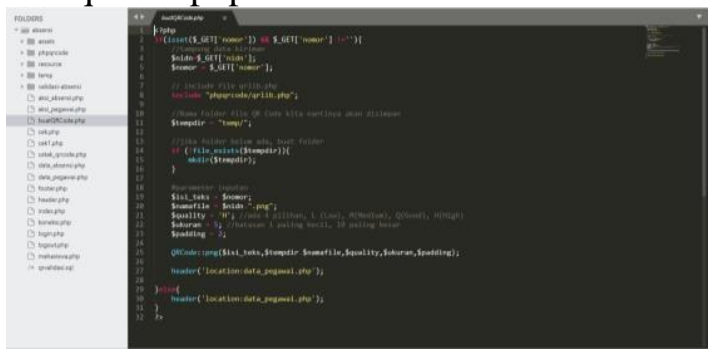

Gambar 9. Source Code Pembuatan QR

$$
\text { Code }
$$

4. Agar QR Code yang dibuat dapat terbaca oleh sistem dilakukan pembuatan file validasi absensi. Berikut adalah isi dari file validasi absensi.

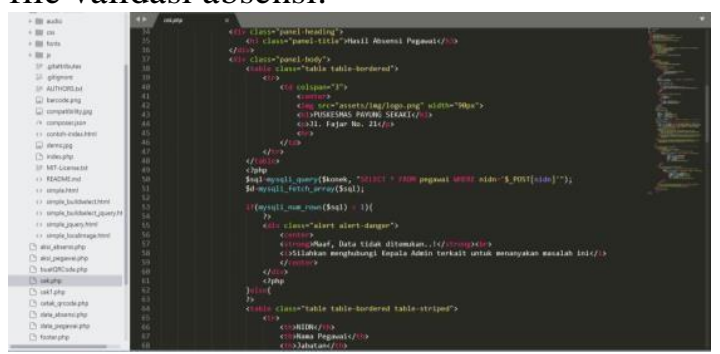

Gambar 10. Source Code Pembuatan Deteksi QR Code

5. Sistem yang dibuat bisa digunakan secara online untuk memudahkan pegawai puskesmas. Untuk membuat sistem menjadi online digunakan website free hosting yaitu https://www.freehostingeu.com/. Berikut adalah gambar dari file manager https://www.freehostingeu.com/.

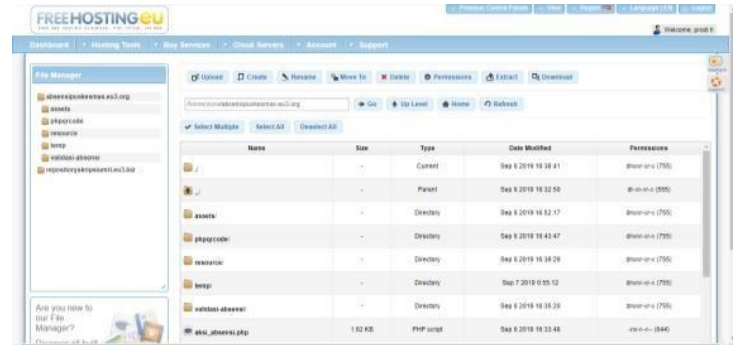

Gambar 11. File Manager Website

6. Untuk membuat sistem dapat digunakan pada smartphone file apk dibuat dengan menggunakan appcreator. Berikut adalah gambaran dari appcreator pembuatan sistem.

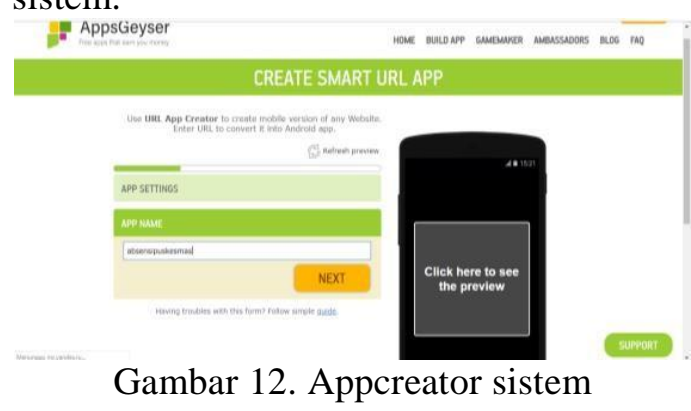

\subsection{Implementasi Sistem}

Halaman utama merupakan halaman yang pertama kali tampil ketika sistem dijalankan. Pada halaman ini untuk dapat masuk kedalam sistem user harus melakukan login terlebih dahulu, sedangkan untuk melakukan absensi pegawai tidak perlu login dulu sebelum melakukan absensi. Berikut ini adalah gambaran implementasi halaman utama.

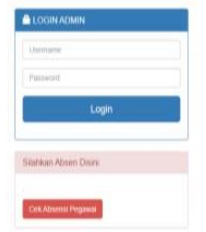

Gambar 13. Halaman Utama Sistem Untuk dapat melakukan absensi, pegawai diberikan QR Code masing-masing terlebih dahulu oleh admin puskesmas dengan menekan tombol buat QR Code, berikut ini adalah gambar hasil implementasi pembuatan QR Code. 


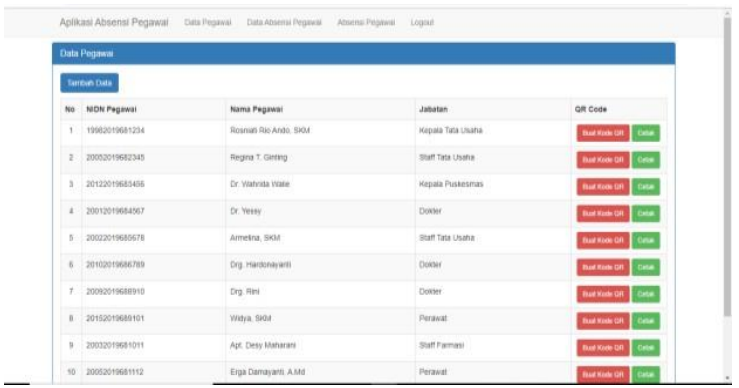

Gambar 14. Halaman Pembuatan QR Code Pegawai

Setelah QR Code berhasil dibuat, pegawai dapat melakukan absensi dengan menggunakan QR Code masing-masing dengan mengakses halaman tambah absensi. Berikut adalah gambar halaman tambah absensi.

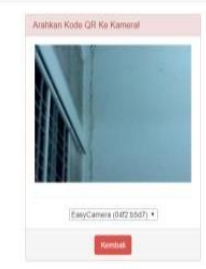

Gambar 15. Halaman Deteksi QR Code Pegawai

Pegawai yang QR Code nya terdeteksi akan tampil halaman yang berisi data pegawai tersebut dan untuk melakukan absensi pegawai harus menekan tombol simpan agar data absensi tersimpan ke dalam sistem. Berikut adalah gambar halaman absensi pegawai.

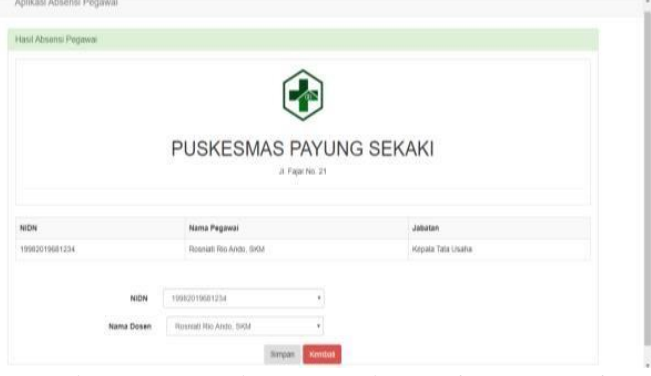

Gambar 16. Halaman Absensi Pegawai

\subsection{Pengujian Sistem}

Dalam penelitian ini pengujian yang dilakukan terhadap aplikasi yaitu pengujian secara fungsional (alpha) dan pengujian pengguna (beta). Metode yang digunakan dalam pengujian ini adalah pengujian blackbox yang berfokus pada fungsional dari aplikasi yang dibangun. Berdasarkan hasil pengujian Alpha yang telah dilakukan, dapat disimpulkan bahwa sistem secara fungsional mengeluarkan hasil yang sesuai dengan yang diharapkan. Dan dari pengujian beta yang telah dilakukan, berdasarkan pilihan kategori jawaban dari kuesioner yang telah disebarkan kepada 10 pengguna, maka dapat disimpulkan bahwa secara fungsional sistem absensi pegawai ini sudah dapat menghasilkan output yang diharapkan dan mudah untuk digunakan sehingga menjadi media absensi bagi pegawai dan penyampaian informasi kehadiran pegawai bagi kepala tata usaha.

4. Kesimpulan

Dalam penelitian skripsi yang berjudul "Penerapan Quick Response (QR) Code Sebagai Absensi Berbasis WEB Di Puskesmas Payung Sekaki Pekanbaru", terdapat beberapa kesimpulan, yaitu :

1. Sistem yang dibuat memudahkan pegawai dalam melakukan absensi

2. Kepala tata usaha dapat dengan mudah untuk mendapatkan informasi kehadiran pegawai Puskesmas Payung Sekaki

3. Meningkatkan produktifitas kerja pegawai Puskesmas Payung Sekaki.

\section{Ucapan Terimakasih}

Terima kasih kepada kedua orang tua, adik kakak yang telah memberikan dukungan baik secara moril dan materil, serta para dosen pembimbing yang sangat membantu atas kelancaran penelitian ini sebagai syarat mendapatkan gelar sarjana strata satu.

\section{Daftar Rujukan}

[1]. Rouillard, J. (2008). Contextual QR Codes, Proceedings of The Third International Multi-Conference On Computing In The Global Information Technology.

[2]. S. Pressman Roger, Ph.D. 2003. Rekayasa Perangkat Lunak Pendekatan Praktisi (Terjemahan Buku I). Yogyakarta : Andi.

[3]. Yuhefizar. 2008. Database Management Menggunakan Microsoft Acces 2003. Jakarta: PT. Elex Media Komputindo.

[4]. "Sublime Text Portal | www.sublimetext.com". 2019 [Online]. [5] Sidik, Betha. 2012. Pemrograman Web dengan PHP. Bandung: Informatika. 
[5]. Sutarman. 2007. Membangun Aplikasi

Web Dengan PHP dan MySQL.

Yogyakarta : Graha Ilmu 